\title{
Improving and predicting the mechanical properties of foamed and stretched composite poly(lactic acid) films
}

\author{
S. Hussain ${ }^{1,2}$, A. R. Dickson ${ }^{1 *}$ \\ ${ }^{1}$ Scion, Private Bag 3020, 3046 Rotorua, New Zealand \\ ${ }^{2}$ International Paper, 6283 Tri-ridge Blvd. Loveland, 45140 Ohio, USA
}

Received 11 May 2018; accepted in revised form 12 July 2018

\begin{abstract}
Foamed poly(lactic acid) films reinforced with micro-crystalline cellulose (MCC), were uniaxially stretched to different ratios. At 10\% (weight) loading MCC particles gave an approximately 3.5 times improvement in stiffness over unreinforced foams. X-ray tomography and image analysis showed that most MCC particles had low aspect ratios, were randomly oriented and well distributed. Stretching did not change the orientation of the MCC particles. Increases in stiffness with stretching were due to the alignment of the foam cell walls. Electron microscopy and image analysis showed that the foam cells were elongated and the walls aligned in the stretch direction. There was a good fit between measured stiffness and micro-mechanical modelling based on a variation of the Mori-Tanaka model for reinforcing particles randomly oriented in 3 dimensions.
\end{abstract}

Keywords: mechanical properties, PLA foam, X-ray tomography, reinforcements, modelling and simulation

\section{Introduction}

\subsection{Background}

Poly(lactic acid) (PLA) is a bio-derived plastic that is used to form bottles, films, food packaging and serviceware. PLA can be sourced from the fermented starch of corn, rice, wheat or sugarcane and unlike polystyrene and some other petroleum sourced plastics, degrades biologically with industrial composting [1-3]. PLA is also readily foamed and can be a replacement for expanded polystyrene because of similar mechanical properties and means of processing $[4,5]$.

Thin films of PLA can be foamed, offering new applications for PLA [6]. Foamed films have been used as wire wraps, tamper-evident seals and packaging labels and liners but most of these foamed films are made from polystyrene and polypropylene [7]. Foamed films are light-weight, can have high gloss and opacity that is suitable for printing [6] and are soft to the touch. There is a limit to light-weighting of foamed films as the stiffness is significantly reduced since it is proportional to foam density [8].

\subsection{Modelling composite foam stiffness}

Polymer foams consist of isolated or interconnected voids/cells containing a specific gas or air. The polymer matrix material surrounds the cells and forms the walls of the foam structure. The stiffness of PLA foams increases with particle reinforcement: glass beads [9], wood flour [10] and wood fibres [11]. For low aspect ratio particles, models have been proposed where the particles are embedded within and reinforce the cell walls. Examples include short glass fibres and beads [12] and micro-crystalline cellulose (MCC) [13]. For models with particles larger than the cell walls, the entire foam cell structure was treated as a homogeneous matrix reinforced by embedded particles [11, 14, 15]. 


\subsection{The effect of stretching on the stiffness of foamed films}

The stiffness of PLA foamed films increases by approximately 4 times when they are mechanically stretched above the glass transition temperature [6]. This large increase in stiffness has also been observed for foamed polypropylene films for both uniaxial [16] and biaxial stretching in both the machine and cross-machine directions $(M D, C D)[17,18]$. There are two proposed mechanisms by which stretching increases the elastic modulus of foamed films: a) an increase in crystallinity and b) alignment of the foam cell walls. Although, the orientation of crystals will have an impact on elastic modulus in plastics, it is proportional to degree of crystallinity [19]. Therefore, we assume that if there are no changes to degree of crystallinity, there will be no changes to crystal orientation. Foaming applies strain hardening effects to the solid plastic material by elongating polymeric chains. This increases the degree of crystallinity and the tensile elastic modulus. Studies by Wang et al. [20] and Garancher and Fernyhough [21] confirmed increases in the crystallinity of PLA by up to $35 \%$ due to expansion from foaming. However, both studies found that increases in crystallinity were limited and subtle with increased levels of foaming. Drumright et al. [22] also found that crystallinity of solid PLA films reached a maximum at a stretch ratio of 4 .

Gibson and Ashby highlighted that when already foamed materials are mechanically stretched the cell walls become aligned in the direction of the stretching [8]. Initially, for unstretched foams tensile deformation of the entire foam will cause the cell walls to bend. Subsequently, the cell walls will align in the direction of the applied load. These aligned cell walls will deform axially, which requires more force than bending and this causes a structural stiffness reinforcement [8].

\subsection{Focus of present study}

In this study we investigated MCC reinforced composite PLA foams (produced through solid-state foaming) that were stretched in the $M D$. We have used a mechanistic model that predicts the foam composite tensile elastic modulus and found a good fit to the model through particle characterisation and comparison to experimental results. An X-ray nano-tomography unit was used to help characterise the MCC particles in the foamed matrix and any changes to the particles due to foaming and stretching. Scanning Electron Microscopy (SEM) was used to characterise the foam cellular structure. The novelty of this study is that it is possible to treat foams (cellular material) as a homogenous matrix when applying micromechanical models to predict the improvements in stiffness from adding fillers. In addition, structural reinforcement from cell wall alignment can explain increases in foam stiffness.

\section{Methods and materials}

\subsection{Solid film preparation}

Pellets of PLA (Ingeo ${ }^{\text {TM }} 3052$ D, NatureWorks LLC, Minnesota, USA) were compounded with MCC powder (Cellulose microcrystalline powder, 435236-1KG, Sigma Aldrich Co. USA). To determine the particle size distribution, the MCC powder was dispersed in water and a drop mounted on a glass slide. The MCC was imaged under cross-polarised illumination (10× PL Fluotar objective) using a Leica DMRB microscope fitted with a Leica EC3 digital camera (Leica Microsystems, Germany). ImageJ (version 1.52b, National Institutes of Health, USA) [23] was used to determine the feret lengths of the individual particles. The median length was $7.5 \mu \mathrm{m}$ and the 25 and $75 \%$ quartiles were 1.7 and $14.0 \mu \mathrm{m}$ respectively. A LABtech $^{\text {TM }}$ vented extruder type LTE 26-40 (LabTech Engineering Co. Ltd, Praksa, Muang, Samutprakarn, Thailand) was used to create composite films of 5 and $10 \mathrm{weight} \%$ (wt $\%$ ) MCC. Control samples $(0 \mathrm{wt} \%$ MCC) were also developed. The following extrusion settings were employed: temperature profile (from feed to die) $180-190^{\circ} \mathrm{C}, 200 \mathrm{rpm}$ screw speed, feeder rate $18 \mathrm{rpm}$, calendering roller temperature $40^{\circ} \mathrm{C}$ and speed $3.2 \mathrm{~m} / \mathrm{s}$ with a nip gap of $0.3 \mathrm{~mm}$.

\subsection{Foaming and stretching composite films}

Solid-state batch foaming with liquid $\mathrm{CO}_{2}$ as a physical blowing agent was employed. The films were impregnated at 0 or $20^{\circ} \mathrm{C}$ and $6000 \mathrm{kPa}$ for $45 \mathrm{~min}$ utes and then placed in a water bath at 80 or $90^{\circ} \mathrm{C}$ where they immediately stretched in all directions. The films were foamed at different $\mathrm{CO}_{2}$ concentrations (approximately $8-15 \mathrm{wt} \%$ ). Before foaming the films were approximately $100 \times 40 \times 0.3 \mathrm{~mm}(M D \times$ $C D \times$ thickness). Through foaming the films stretched to approximately $280-300 \mathrm{~mm}$ in the $M D(\sim 3$ times), $100-120 \mathrm{~mm}$ in the $C D$ and $0.6 \mathrm{~mm}$ in thickness. The foamed films were stretched further ( $M D$ only) at 80 or $90^{\circ} \mathrm{C}$ using hand operated metallic clamps 
to increase the stretch ratio (length of sample after foaming and stretching divided by the original unfoamed length) beyond 3 times resulting in final stretch ratios up to approximately 6 times. The temperatures used were above the glass transition temperature of the PLA grade used. This resulted in a decrease in stretch ratio in the $C D$ and in thickness. The final stretch ratio is a combination of the initial expansion due to foaming and then further mechanical stretching.

\subsection{Mechanical and material properties}

Tensile testing on foamed films was performed using a TA Instruments RSA-G2 (TA Instruments - Water LCC, Delaware, USA) at $23{ }^{\circ} \mathrm{C}$ and $50 \%$ relative humidity to determine the tensile elastic modulus. Samples tested were $15 \mathrm{~mm}$ in length and $3 \mathrm{~mm}$ in width and the strain rate was $0.03 \mathrm{~mm} / \mathrm{s}$. Both $M D$ and $C D$ samples were tested.

A TA instrument Discovery DSC (TA Instruments Water LCC, Delaware, USA) was used to determine the crystallinity of the foamed samples. Degree of crystallinity [\%] was calculated based on a melting energy of $93 \mathrm{~J} / \mathrm{g}$ for $100 \%$ crystalline PLA polymer as described in a previous study [24]. Samples of different stretch ratios were evaluated.

Due to the foaming and stretching technique employed, it was very difficult to develop replicate samples with identical final stretch ratios for tensile testing. Therefore, a range of stretch ratios was targeted to observe general trends for the tensile modulus.

\subsection{Materials visualisation}

A Bruker SkyScan 1272 (Bruker micro CT, Kontich, Belgium) was used for X-ray tomography. The settings were: $27 \mathrm{kV}$ accelerating voltage, $155 \mu \mathrm{A}$ current density, a scanning resolution of $0.5 \mu \mathrm{m}$ voxels and 360 degree rotation with images generated at 0.2 degree intervals. Automatic thresholding was performed using the resident ImageJ (version 1.51e) implementation of the entropy based Yen method $[25,26]$. Manual thresholding was also used as a comparison. The images were cropped to approximately $2.4 \mathrm{~mm}$ in the $X$ (test $/ \mathrm{stretch} / M D$ ) direction and $1.3 \mathrm{~mm}$ in the $Z$ direction (perpendicular to the $X$ direction). The segmented unstretched sample and coordinate system are shown in Figure 1.

For analysis the image resolution was decreased to $1 \mu \mathrm{m}$ voxels. The particle analyser component in ImageJ (BoneJ v1.4.1 [27]) that uses fitted ellipses was

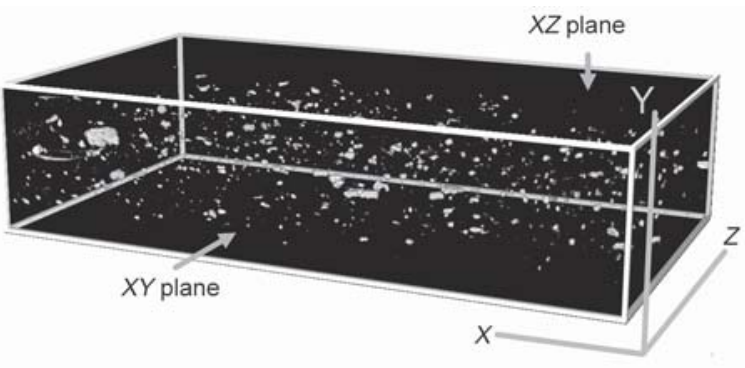

Figure 1. Segmented unstretched sample showing coordinate system. Stretching is performed along the $X$ axis. Approximate dimension: $X=2.4 \mathrm{~mm} ; Y=$ $0.3 \mathrm{~mm} ; Z=1.3 \mathrm{~mm}$.

used to determine particle volume, aspect ratio and $3 \mathrm{D}$ particle orientation vectors on particles with volumes $\geq 27 \mu \mathrm{m}^{3}(3 \times 3 \times 3$ pixels $)$. The polar angle $\theta$ was determined according to Figure 2. Two-dimensional analysis was also performed on individual image slices of the full 3D stack. The distance between the centres of neighbouring particles was determined using the ImageJ resident Voronoi analysis. Particle distribution was estimated by calculating the coefficient of variation (standard deviation/mean) of the distance between particles (CoV interparticle space) [28]. For SEM analysis a razor blade was used to expose an $X Z$ plane (see Figure 1) within the thickness of the film. They were coated with chromium using an Emitech K575X sputter coater (Quorum Technologies Ltd, Kent, United Kingdom) and imaged using

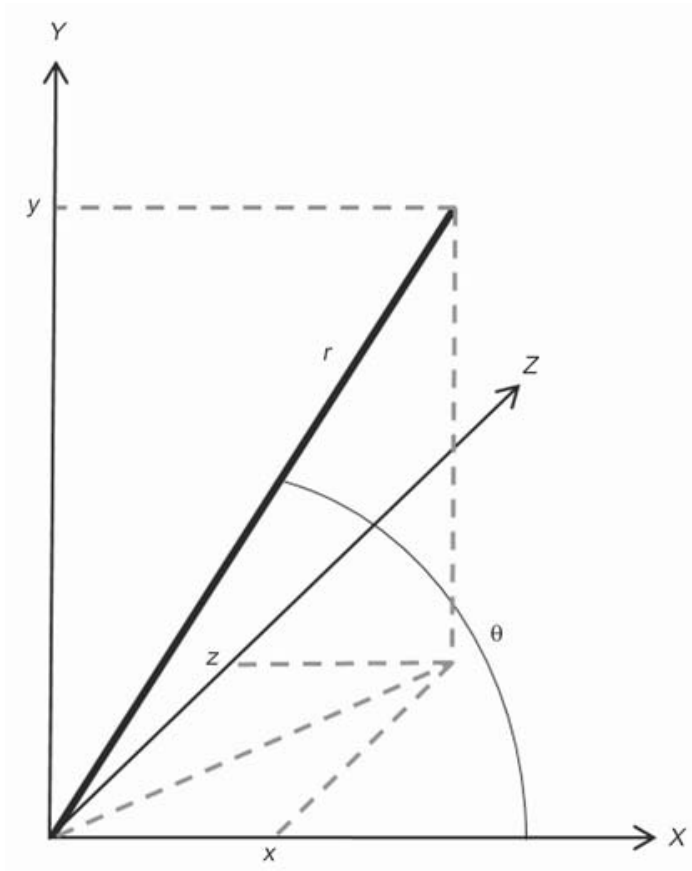

Figure 2. Determining the polar angle $(\theta)$ of the fibre axis ( $r$ ) from unit vector components $x, y, z . X=$ test/stretch direction, $Y=$ foam thickness. 


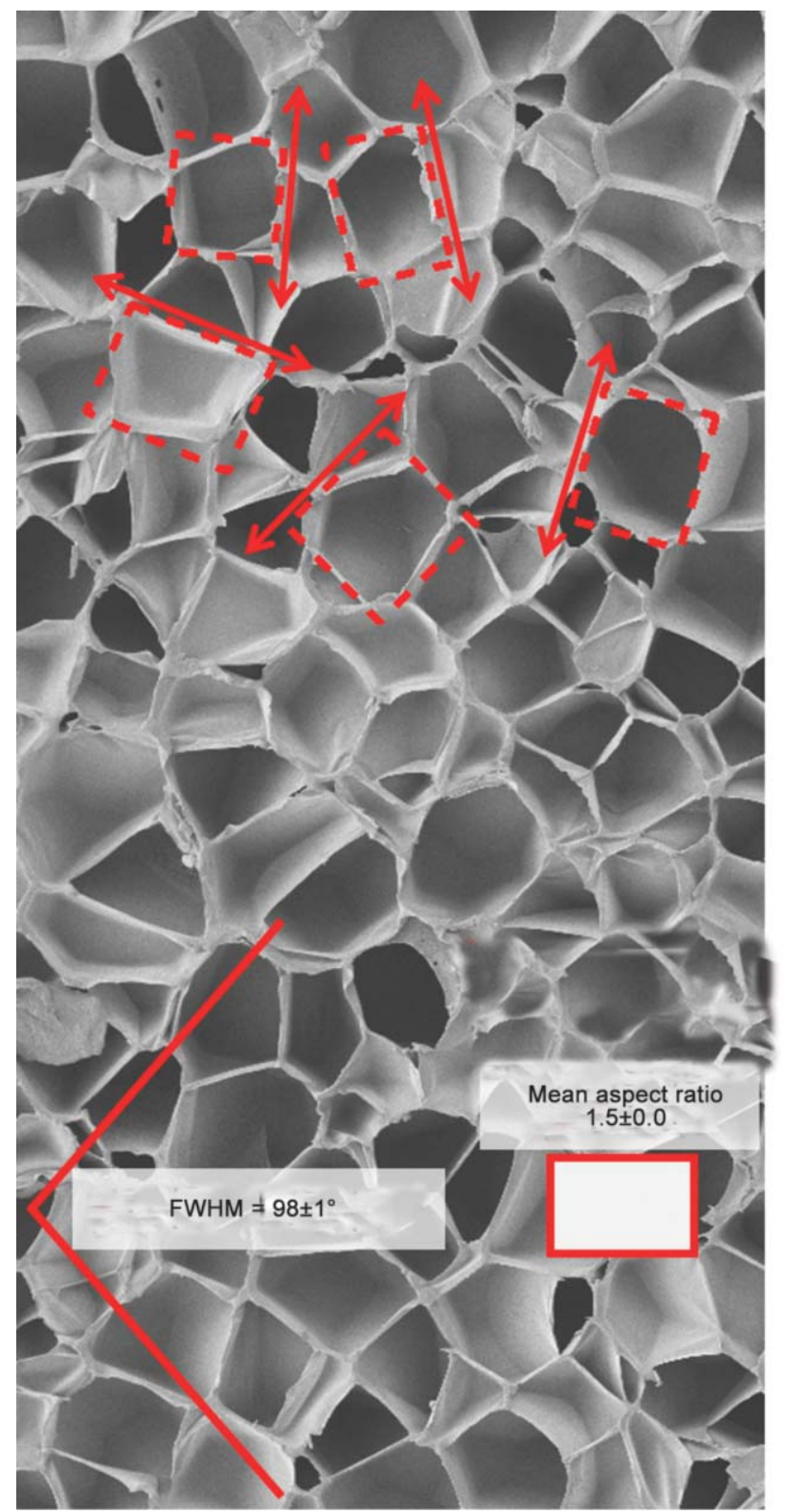

a)

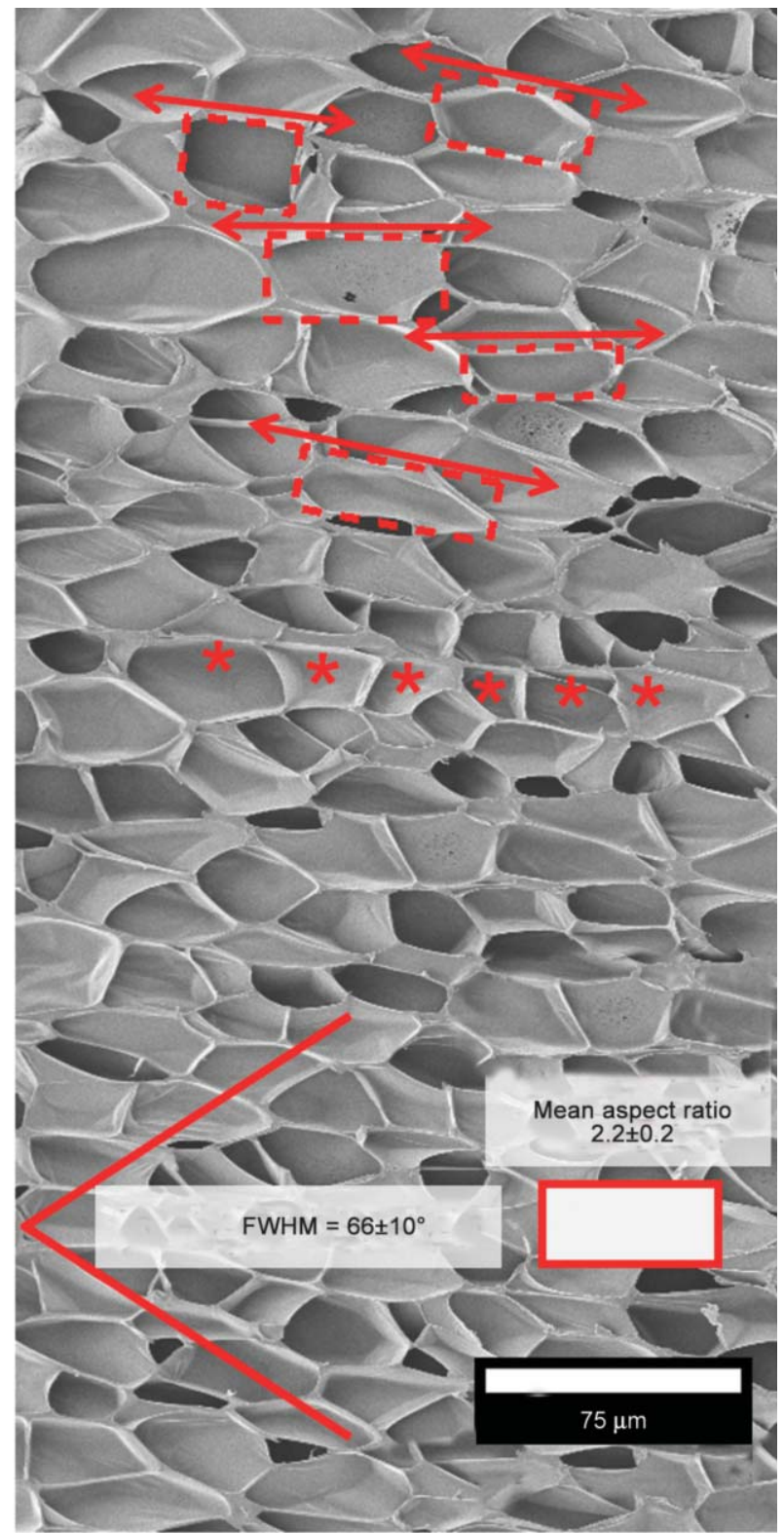

b)

Figure 3. Representative SEM images of unstretched (a) and stretched (3.9 final stretch ratio) (b) unreinforced foams. Dotted rectangles are examples of best fit rectangles for selected cells. Arrows indicate the orientation of the rectangle long axis. Asterisks (*) indicate adjacent cells with walls on the same plane and aligned in the stretch direction. Mean angular dispersion (FWHM) and rectangle aspect ratios are measured from 100 cells selected from each of 6 images per sample.

a JEOL JSM6700F (JEOL Ltd, Tokyo, Japan). Six images were taken per sample. One hundred foam cells were randomly selected per image, using a random number algorithm, and their perimeters traced manually. An algorithm determined the smallest rectangle (best fit rectangle) enclosing the perimeter. Cell orientation was defined as the angle of the rectangle long axis to the horizontal. Cell shape was defined by the aspect ratio of the best fit rectangle (long axis/short axis) (see Figure 3). Analysis was based on the mean values from each image (i.e. $n=6$ ). Image analysis was performed using ImageJ.
The orientations of particles (X-ray tomography) and voids (SEM) are presented relative to the $X$ direction $\left(X=0^{\circ}\right)$ and angles range from -90 to $+90^{\circ}$. The variation in particle/void orientation was estimated by determining the Full Width Half Maximum (FWHM) of a Gaussian curve fitted to the angle frequency data.

\section{Results and discussion}

\subsection{MCC particle aspect ratio and placement in foam matrix}

Based on fitted ellipses to over 700 particles (dependant on sample and threshold, X-ray tomography), 
Table 1. 3D particle analysis based on fitted ellipses from X-ray tomography.

\begin{tabular}{|c|c|c|c|c|c|c|}
\hline \multirow{2}{*}{ Sample } & \multirow{2}{*}{ Threshold $^{b}$} & \multirow{2}{*}{$\begin{array}{c}\text { Number of } \\
\text { particles }\end{array}$} & \multicolumn{2}{|c|}{$\Theta^{\mathrm{a}}$} & \multicolumn{2}{|c|}{ Aspect ratio } \\
\hline & & & mean & FWHM $^{\mathrm{c}}$ & mean & Std. Dev. \\
\hline Stretched & M1 (53) & 1350 & -2.0 & 99.3 & 3.0 & 5.4 \\
\hline Stretched & (64) & 729 & 0.5 & 100.2 & 3.4 & 2.5 \\
\hline Unstretched & (99) & 3667 & -1.6 & 98.5 & 4.2 & 6.5 \\
\hline Unstretched & M1 (126) & 1440 & -1.5 & 98.2 & 3.7 & 5.0 \\
\hline Unstretched & M2 (144) & 983 & -1.5 & 98.4 & 3.1 & 2.2 \\
\hline
\end{tabular}

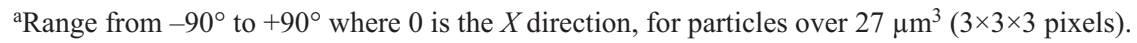

${ }^{\mathrm{b}} M=$ manual threshold; $Y=$ Yen threshold; $(\ldots)$ contains threshold level used. Greyed data $=$ similar thresholded total particle volumes.

${ }^{\mathrm{c}}$ Full Width Half Maxiumum of fitted Gaussian distribution.

the mean $3 \mathrm{D}$ aspect ratios were in the range of 3.0 4.2 for the range of different thresholds used (see Table 1). SEM imaging was also performed but we were unable to obtain sufficient contrast between the MCC particles and PLA for meaningful analysis. We assumed that any matrix reinforcement from the particles can be explained by the Mori-Tanaka Theory for short-fibre composites [29]. We assumed the MCC particles were embedded in the matrix material $[10,13,14]$.

\subsection{MCC particle orientation and particle distribution}

For the two samples the mean $\theta$ was approximately 0 indicating there was no strong deviation from the $X$ axis over the range of different thresholds and there was no evidence that particle orientation analysis was influenced by thresholding (see Table 1). The FWHM of $\theta$ were in the range of 98 to 100 degrees, indicating a large variability in angle which we regarded as being essentially random. We therefore assumed that particle alignment was random for the unstretched sample and that stretching did not result in a change of particle alignment relative to the stretch direction. We interpreted from this that during stretching at 80 or $90^{\circ} \mathrm{C}$ there was minimal or no alignment of the MCC particles due to minimal stress transfer from the softened surrounding PLA matrix material. The CoV of the interparticle spaces for both the stretched and unstretched foams was in the approximate range of $0.3-0.5$ (data not shown). A value of approximately 0.36 is considered to represent a random distribution [28]. This suggests the MCC particles were well distributed within the foam matrix.

\subsection{Cell wall alignment microscopy}

Stretching resulted in a significant change in foam cell morphology (see Figure 3). Unstretched foam cells had a mean aspect ratio of $1.5 \pm 0.0$ and a dispersion
(FWHM) of $98 \pm 1^{\circ}$. Stretching to a final $M D$ stretch ratio of 3.9 increased the cell aspect ratio to $2.2 \pm 0.2$ and decreased the dispersion to $66 \pm 10^{\circ}$. This indicated that stretching both elongated the cells (increase in aspect ratio) and aligned the walls of individual cells in the stretch direction (decreased dispersion). In places, this alignment extended to several adjacent cells in the stretch direction (see Figure 3).

\subsection{Increases in normalised tensile elastic modulus}

The normalised tensile modulus (tensile modulus/ sample density) increased exponentially with stretch ratio (see Figure 4). The modulus was normalised by density due its large effect on the modulus of foams

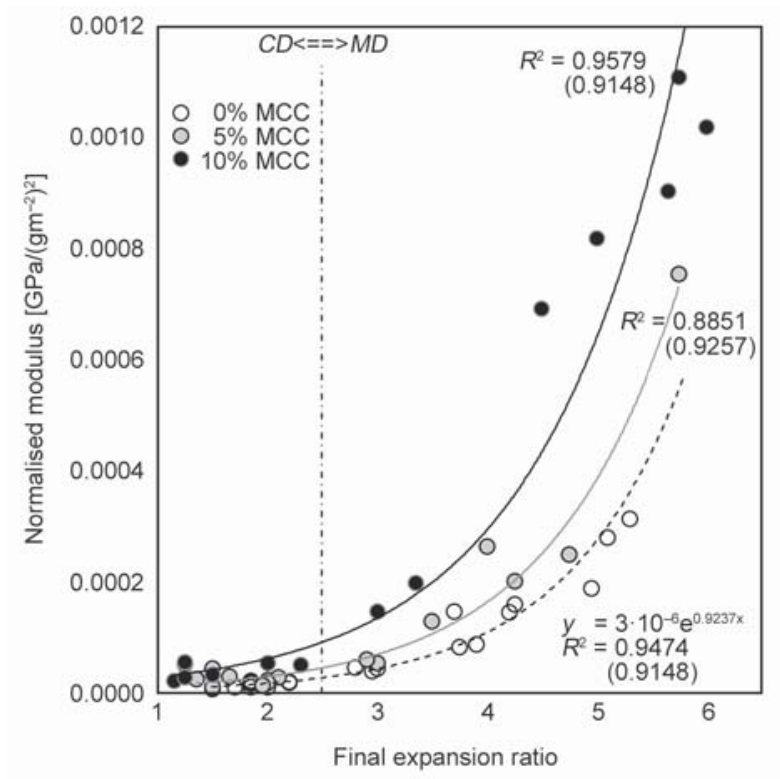

Figure 4. $M D$ and $C D$ normalised tensile modulus with stretch ratio for foams stretched in the $M D$. Stretch ratios above 2.5 are $M D$ data and below 2.5 are $C D$ data. There is an increase in tensile modulus with higher loadings of MCC particles and larger final stretch ratio. $R_{2}$ values shown without brackets are for both the $M D$ and $C D$ data. The values in brackets are for the $M D$ data only. 
[8]. The area density was used for normalisation since the thickness was in the order of 1000 times smaller than the foamed lengths in the $M D$ and $C D$ and subtle changes to the thickness would have significant effects on the normalised results but mechanically limited effects. At the highest stretch ratios in the $M D$, the 10 and $5 \mathrm{wt} \%$ MCC particle films showed normalised elastic moduli approximately 3.5 and 2 times higher, respectively, than unreinforced foamed films (see Figure 4).

\subsection{Cell wall alignment effect on normalised tensile modulus}

For foamed films, the process of foaming will increase the degree of crystallinity from the alignment of polymeric chains $[20,21]$. Table 2 shows that foaming increased the MD stretch ratio for both the pure and composite PLA foams and the degree of crystallinity was also increased to approximately $30 \%$. Stretching further increased the $M D$ stretch ratio but the degree of crystallinity was unchanged. However, there was a significant increase in tensile modulus. This means the observed increases in modulus cannot be attributed to increased crystallinity. It is also interesting to note that the degree of crystallinity for $10 \mathrm{wt} \%$ MCC samples is slightly (but not statistically significantly) lower than the degree of crystallinity for the pure foams, however, the tensile modulus significantly increases. This suggests the particle reinforcement is more significant than degree of crystallinity.

With uniaxial stretching in the $M D$, the cells deformed and the cell walls aligned (see Figure 3 ) which led to structural strain hardening and reinforcement through the cell walls $[6,8]$. In the $\mathrm{CD}$ there was no cell wall alignment or structural strain hardening. This means the exponential relationship between the normalised tensile elastic modulus of the foamed

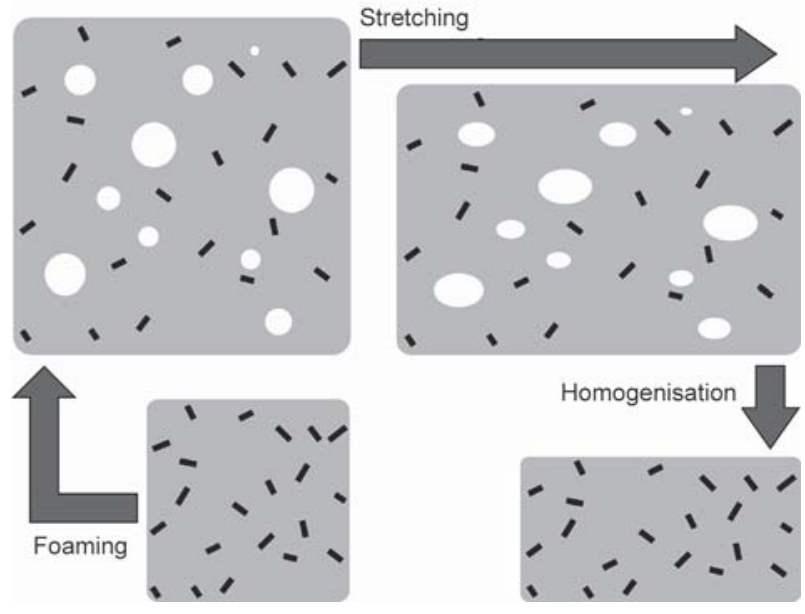

Figure 5. Reinforced foamed structure represented as a homogeneous matrix with the same volume. Foaming leads to voids/cells are ignored when determining the composite elastic modulus.

films and stretch ratio can be attributed solely to cell wall alignment.

\subsection{Mechanistic model for foam reinforcement by MCC particles}

We used a mechanistic model to explain the increase in normalised tensile elastic modulus with increased MCC particle content and final stretch ratio (stretching in $M D$ ). From previous studies [11, 14], we assumed that an equivalent solid homogeneous matrix can represent the foamed cellular structure in the model (see Figure 5). The cells contained air which does not contribute to the stiffness. However, we assumed that the remaining solid PLA matrix and the embedded MCC particles did contribute to the stiffness. Therefore, by ignoring the hollow cells, an equivalent solid composite homogeneous matrix was used to predict the composite tensile elastic modulus. We tested this mechanistic model by using micromechanical modelling to predict the normalised tensile elastic modulus of the equivalent composite

Table 2. Degree of crystallinity and elastic modulus.

\begin{tabular}{|c|c|c|c|c|}
\hline Sample & Treatment & $\begin{array}{l}\text { Final stretch ratio } \\
(M D, C D)\end{array}$ & $\begin{array}{c}\text { Degree of crystallinity } \\
{[\%]^{*}}\end{array}$ & $\begin{array}{c}\text { Normalised } M D \text { elastic modulus } \\
{\left[\mathrm{GPa} /\left(\mathrm{g} / \mathrm{m}^{2}\right)^{2}\right]}\end{array}$ \\
\hline \multirow{3}{*}{ Pure PLA film } & No foaming & $1.0,1.0$ & 0 & N/A \\
\hline & Foamed & $2.8,2.8$ & $33.0 \pm 6.3(2)$ & $4.6 \cdot 10^{-5}$ \\
\hline & Foamed and stretched & $4.1,1.8$ & $30.4 \pm 2.6(2)$ & $1.4 \cdot 10^{-4}$ \\
\hline \multirow{3}{*}{$10 \mathrm{wt} \%$ MCC-PLA film } & No foaming & $1.0,1.0$ & 0 & $\mathrm{~N} / \mathrm{A}$ \\
\hline & Foamed & $2.5,2.5$ & $27.8 \pm 2.3(5)$ & $1.0 \cdot 10^{-4}$ \\
\hline & Foamed and stretched & $5.5,1.5$ & $28.3 \pm 2.7(3)$ & $1.0 \cdot 10^{-3}$ \\
\hline
\end{tabular}

${ }^{*} \pm 95 \%$ confidence intervals. The number in brackets (...) is the number of replicates.

The crystallinities were not significantly different (single factor ANOVA, $\alpha=0.05$ ). 
homogeneous matrix and compared this to the experimental results.

\subsection{Specifics for the mechanistic model}

The Mori and Tanaka theory was used to predict the composite homogeneous matrix elastic modulus [29]. The theory predicted the elastic modulus of composite materials well [30-32]. The theory is an improvement on the inclusion theory of Eshelby [33]. In this study, we used the simplifications to the MoriTanaka model developed by Tandon and Weng [34, 35]. These simplifications were designed for short particles that are either unidirectional in two-dimensions or randomly oriented in three dimensions. Derivations of the equations used and explanations for the simplifications can be found in [34] for two dimensions and [35] for three dimensions.

The properties to calculate the composite elastic modulus from the Mori-Tanaka model used are: PLA matrix (tensile modulus from equation in Figure 4, Poisson's ratio 0.25 , solid material density $1.2 \mathrm{~g} / \mathrm{cm}^{3}$, density measured for the entire foam, volume fraction 0.918 ) and MCC particles (tensile modulus $25 \mathrm{GPa}$ [36], Poisson's ratio 0.3 [37], density $1.5 \mathrm{~g} / \mathrm{cm}^{3}$ [38], volume fraction 0.081 ). The volume fractions were calculated from the weight fractions and material densities. Five different aspect ratios were used (2.1, $2.7,4.1,6.2,9.3)$ as they corresponded to the $25^{\text {th }}$ through to $95^{\text {th }}$ percentile of aspect ratio size (M1

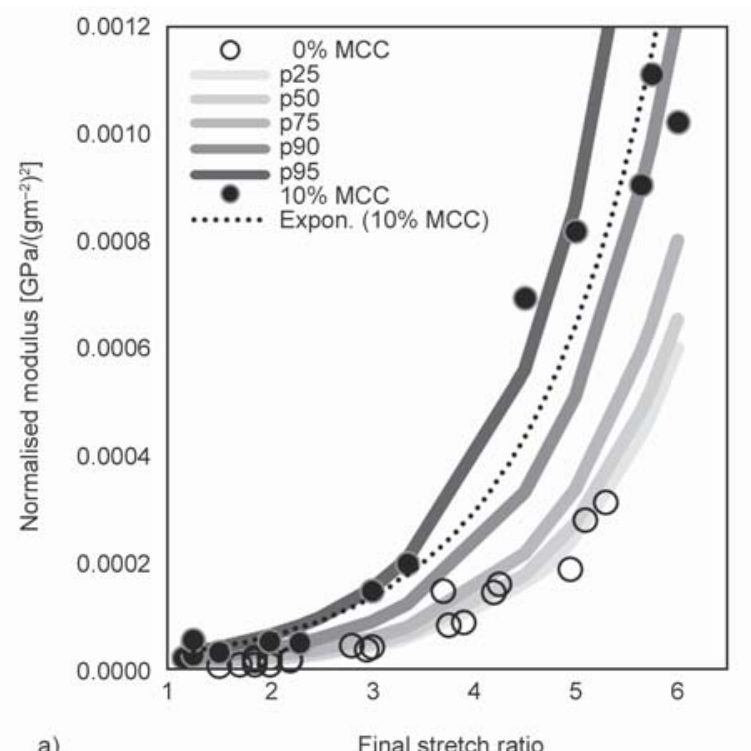

threshold, 1350 particles, see Table 1) from the Xray tomography data.

\subsection{Comparing the mechanistic model results to experimental results}

The mechanistic model proposed and the MCC particle dimensional values extracted from the X-ray tomography analysis showed a good fit to the composite normalised tensile elastic modulus at the different stretch ratios for the $10 \mathrm{wt} \%$ composite samples (see Figure 6).

The composite elastic modulus was predicted well for both the two-dimensional and three-dimensional particle orientation cases. However, the three dimensional scenario predicted the composite elastic modulus better across all stretch ratios than the two-dimensional scenario. The three-dimensional scenario assumes random orientation whereas the two-dimensional scenario assumes unidirectional orientation. This confirmed the tomography analysis which suggested that the MCC particles were randomly dispersed in three dimensions. The higher percentile aspect ratio (p95) best predicted the composite elastic modulus, whereas the very low aspect ratio particles (p25) did not reinforce the matrix as much.

The results suggest that the fibre reinforcement capability is increased at higher stretch ratios. This is related to the exponential increase in PLA matrix elastic modulus due to cell wall alignment at higher stretch

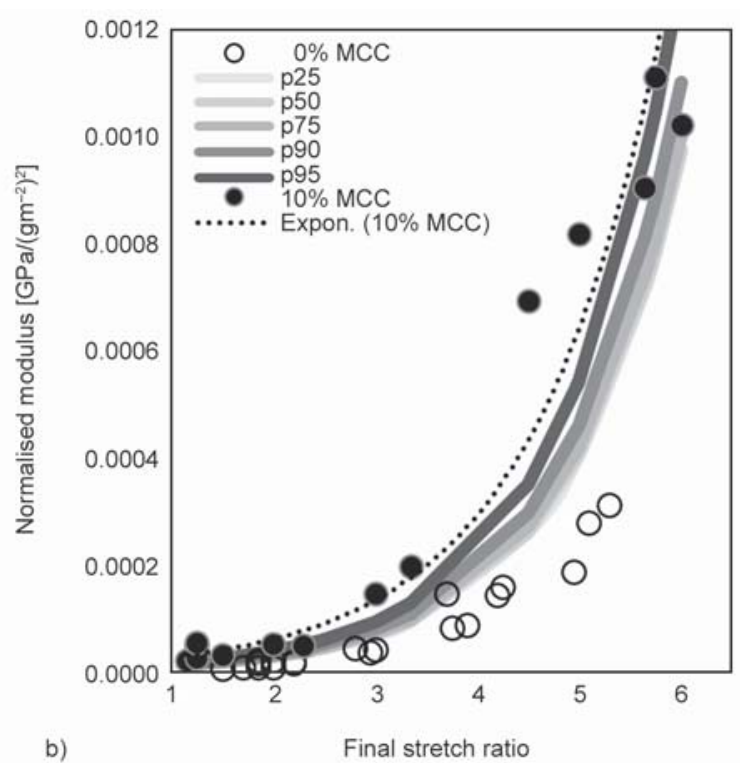

Figure 6. Mechanistic model fitted to $10 \% \mathrm{MCC}$ data for a range of aspect ratios. a) the $2 \mathrm{D}$ case and b) the $3 \mathrm{D}$ case. Different aspect ratio percentiles $\left(25^{\text {th }}, 50^{\text {th }}, 75^{\text {th }}, 90^{\text {th }}\right.$ and $\left.95^{\text {th }}\right)$ were used. This highlights that very low aspect ratio particles $\left(25^{\text {th }}\right.$ percentile) do not contribute to the increased composite stiffness. 
ratios. A weakly foamed matrix will preferentially deform, however, a stiffer matrix will transfer more stress to the MCC particles.

\section{Conclusions}

The normalised tensile elastic modulus of PLA foams with embedded MCC particles increased exponentially with uniaxial stretching in the $M D$. This increase was attributed mainly to cell wall alignment in the $M D$. This theory was supported with microscopic analysis and unchanged degree of crystallinity from measurements using a DSC. The elastic modulus was higher for foams with higher MCC content. Specifically, there was an increase of 3.5 times for $10 \mathrm{wt} \%$ and 2 times for $5 \mathrm{wt} \%$ MCC foamed films at the highest stretch ratios.

In order to understand the stiffness reinforcement from increased particle content a mechanistic model was proposed and tested. It was assumed that the cellular structure can be replaced with an equivalent solid homogeneous matrix with embedded MCC particles. X-ray tomography was used to determine that the particles had low aspect ratios and random orientation. Particle orientation was not influenced by the threshold used meaning that, within reason, particle orientation analysis was not dependent on the selection of a correct threshold level. Using a variation of the Mori-Tanaka theory which assumes random orientation in 3 dimensions, good correlation between predicted and experimental results for the composite elastic modulus was found for a wide range of measured aspect ratios.

\section{Acknowledgements}

The authors would like to acknowledge Sylke Campion, Meeta Patel, Gildas Lebrun, Samir Shah and Marie-Joo Le Guen for their technical assistance. Dane Gerneke performed the X-ray tomographic imaging. Kate Parker, Sarah Heine, Mathias Sorieul and Elspeth MacRae provided comments and suggestions on the manuscript. The funding for this work was provided by the Biopolymer Network Ltd through the grant number BPLY 1301 associated with the Ministry of Business, Innovation and Employment (New Zealand).

\section{References}

[1] Musioł M., Sikorska W., Adamus G., Janeczek H., Kowalczuk M., Rydz J.: (Bio)degradable polymers as a potential material for food packaging: Studies on the (bio)degradation process of PLA/(R,S)-PHB rigid foils under industrial composting conditions. European Food Research and Technology, 242, 815-823 (2016).

https://doi.org/10.1007/s00217-015-2611-y
[2] Musioł M., Sikorska W., Adamus G., Janeczek H., Richert J., Malinowski R., Jiang G., Kowalczuk M.: Forensic engineering of advanced polymeric materials. Part III - Biodegradation of thermoformed rigid PLA packaging under industrial composting conditions. Waste Management, 52, 69-76 (2016).

https://doi.org/10.1016/j.wasman.2016.04.016

[3] Stloukal P., Koutny M., Sedlarik V., Kucharczyk P.: Biodegradation of high molecular weight polylactic acid. in 'AIP Conference Proceedings. Ischia, Italy' Vol 1459, 20-22 (2012).

[4] Nofar M., Park C. B.: Poly (lactic acid) foaming. Progress in Polymer Science, 39, 1721-1741 (2014). https://doi.org/10.1016/j.progpolymsci.2014.04.001

[5] Dean K., Bateman S., Filippou C., Nguyen T., Toikka G., Yu L., Yuan Q.: A biodegradable replacement for expanded polystyrene (EPS) foam. in 'Society of Plastics Engineers - EUROTECH 2013. Lyon, France’ 372-376 (2013).

[6] Hussain S., Parker K., Garancher J-P.: Investigating foamed polylactic acid films through cell structure alteration and processing conditions. Journal of Cellular Plastics, 53, 513-523 (2017).

https://doi.org/10.1177/0021955X17695091

[7] Schut J. H.: Foamed films find new niches. Plastics Technology, 48, 48-55 (2002).

[8] Gibson L., Ashby M.: Cellular solids: Structure and properties. Cambridge University Press, Cambridge (1997).

[9] Yao R., Yao Z., Zhou J., Liu P.: Mechanical and acoustical properties of polylactic acid based multilayer-structured foam biocomposites. Journal of Reinforced Plastics and Composites, 35, 785-795 (2016). https://doi.org/10.1177/0731684416629762

[10] Ludwiczak J., Kozlowski M.: Dynamic mechanical properties of foamed polylactide and polylactide/wood flour composites. Journal of Biobased Materials and Bioenergy, 9, 227-230 (2015). https://doi.org/10.1166/jbmb.2015.1502

[11] Neagu R. C., Cuénoud M., Berthold F., Bourban P. E., Gamstedt E. K., Lindström M., Månson J. A. E.: Processing and mechanical properties of novel wood fibre composites foams. in 'ICCM International Conference on Composite Materials, Edinburgh, United Kingdom' (2009).

[12] Cotgreave T., Shortall J. B.: The fracture toughness of reinforced polyurethane foam. Journal of Materials Science, 13, 722-730 (1978). https://doi.org/10.1007/BF00570506

[13] Hussain S., Kortschot M. T.: Polyurethane foam mechanical reinforcement by low-aspect ratio micro-crystalline cellulose and glass fibres. Journal of Cellular Plastics, 51, 59-73 (2015).

https://doi.org/10.1177/0021955X14529137 
[14] Masi P N. L., Nicolais L., Mazzola M., Narkis M.: Tensile properties of fiberglass-reinforced polyester foams. Journal of Applied Polymer Science, 28, 1517-1525 (1983). https://doi.org/10.1002/app.1983.070280423

[15] Hussain S., Chang L-C., Kortschot M. T.: Understanding the effects of high aspect ratio fibers on the mechanical reinforcement of soybean based polyurethane foam. Cellular Polymers, 33, 1-20 (2014).

[16] Dontula N., Bomba R., Heath T., Benson J., Sprinz P.: Foamed and oriented polypropylene films. Journal of Cellular Plastics, 43, 145-156 (2007). https://doi.org/10.1177/0021955X06074675

[17] Breil J.: Added value speciality films produced with sequential and simultaneous stretching lines. in 'Special Plastics Films 2002 Global film markets and developments. $18^{\text {th }}$ Annual World Congress. Zurich, Switzerland' 1-32 (2002).

[18] Breil J.: Oriented film technology. in 'Multilayer flexible packaging: Technology and applications for the food, personal care, and over-the-counter pharmaceutical industries' (ed.: Wagner J. R.) William Andrew, Norwich, 119-136 (2009).

[19] Sadeghi F., Tabatabaei S. H., Ajji A., Carreau P. J.: Properties of uniaxially stretched polypropylene films: Effect of drawing temperature and random copolymer content. Canadian Journal of Chemical Engineering, 88, 1091-1098 (2010). https://doi.org/10.1002/cjce.20372

[20] Wang X., Kumar V., Li W.: Effect of heating and stretching on PLA crystallization during solid-state foaming using sub-critical $\mathrm{CO}_{2}$. in 'Society of Plastics Engineers - Global Plastics Environmental Conference 2010, GPEC 2010. Orlando, USA' (2010).

[21] Garancher J-P., Fernyhough A.: Expansion and dimensional stability of semi-crystalline polylactic acid foams. Polymer Degradation and Stability, 100, 21-28 (2014). https://doi.org/10.1016/j.polymdegradstab.2013.12.037

[22] Drumright R. E., Gruber P. R., Henton D. E.: Polylactic acid technology. Advanced Materials, 12, 1841-1846 (2000).

https://doi.org/10.1002/15214095(200012)12:23<1841::AID-ADMA1841>3.0.CO;2-E

[23] Schneider C. A., Rasband W. S., Eliceiri K. W.: NIH image to ImageJ: 25 years of image analysis. Nature Methods, 9, 671-675 (2012).

[24] Cicero J. A., Dorgan J. R., Janzen J., Garrett J., Runt J., Lin J. S.: Supramolecular morphology of two-step, melt-spun poly(lactic acid) fibers. Journal of Applied Polymer Science, 86, 2828-2838 (2002). https://doi.org/10.1002/app.11267

[25] Yen J. C., Chang F. J., Chang S.: A new criterion for automatic multilevel thresholding. IEEE Transactions on Image Processing, 4, 370-378 (1995).

https://doi.org/10.1109/83.366472
[26] Sezgin M., Sankur B.: Survey over image thresholding techniques and quantitative performance evaluation. Journal of Electronic Imaging, 13, 146-168 (2004). https://doi.org/10.1117/1.1631315

[27] Doube M., Kłosowski M. M., Arganda-Carreras I., Cordelières F. P., Dougherty R. P., Jackson J. S., Schmid B., Hutchinson J. R., Shefelbine S. J.: BoneJ: Free and extensible bone image analysis in ImageJ. Bone, 47, 1076-1079 (2010). https://doi.org/10.1016/j.bone.2010.08.023

[28] Yang N., Boselli J., Sinclair I.: Simulation and quantitative assessment of homogeneous and inhomogeneous particle distributions in particulate metal matrix composites. Journal of Microscopy, 201, 189-200 (2001). https://doi.org/10.1046/j.1365-2818.2001.00766.x

[29] Mori T., Tanaka K.: Average stress in matrix and average elastic energy of materials with misfitting inclusions. Acta Metallurgica, 21, 571-574 (1973).

https://doi.org/10.1016/0001-6160(73)90064-3

[30] Gajjela S., Ramachandran V., Somasekharan J.: Influence of interphase material and clay particle shape on the effective properties of epoxy-clay nanocomposites. Composites Part B: Engineering, 88, 11-18 (2016). https://doi.org/10.1016/j.compositesb.2015.11.002

[31] Zare Y.: Development of simplified Tandon-Weng solutions of Mori-Tanaka theory for Young's modulus of polymer nanocomposites considering the interphase. Journal of Applied Polymer Science, 133, 43816/14381/7 (2016).

https://doi.org/10.1002/app.43816

[32] Christensen R. M.: A critical evaluation for a class of micro-mechanics models. Journal of the Mechanics and Physics of Solids, 38, 379-404 (1990). https://doi.org/10.1016/0022-5096(90)90005-O

[33] Eshelby J. D.: The determination of the elastic field of an ellipsoidal inclusion, and related problems. Proceedings of the Royal Society of London. Series A: Mathematical and Physical Sciences, 241, 376-396 (1957). https://doi.org/10.1098/rspa.1957.0133

[34] Tandon G. P., Weng G. J.: The effect of aspect ratio of inclusions on the elastic properties of unidirectionally aligned composites. Polymer Composites, 5, 327-333 (1984). https://doi.org/10.1002/pc. 750050413

[35] Tandon G. P., Weng G. J.: Average stress in the matrix and effective moduli of randomly oriented composites. Composites Science and Technology, 27, 111-132 (1986). https://doi.org/10.1016/0266-3538(86)90067-9

[36] Eichhorn S. J., Young R. J.: The Young's modulus of a microcrystalline cellulose. Cellulose, 8, 197-207 (2001). https://doi.org/10.1023/A:1013181804540

[37] Roberts R. J., Rowe R. C., York P.: The Poisson's ratio of microcrystalline cellulose. International Journal of Pharmaceutics, 105, 177-180 (1994). https://doi.org/10.1016/0378-5173(94)90463-4

[38] Sun C.: True density of microcrystalline cellulose. Journal of Pharmaceutical Sciences, 94, 2132-2134 (2005). https://doi.org/10.1002/jps.20459 